\title{
Urgences
}

\section{Poaimes pour ne plus être seul (extraits)}

\section{Rémi Béland}

Numéro 3, 4e trimestre 1981

URI : https://id.erudit.org/iderudit/025046ar

DOI : https://doi.org/10.7202/025046ar

Aller au sommaire du numéro

Éditeur(s)

Urgences

ISSN

0226-9554 (imprimé)

1927-3924 (numérique)

Découvrir la revue

Citer ce document

Béland, R. (1981). Poaimes pour ne plus être seul (extraits). Urgences, (3), 59-61. https://doi.org/10.7202/025046ar

Ce document est protégé par la loi sur le droit d'auteur. L’utilisation des services d’Érudit (y compris la reproduction) est assujettie à sa politique d'utilisation que vous pouvez consulter en ligne.

https://apropos.erudit.org/fr/usagers/politique-dutilisation/
Cet article est diffusé et préservé par Érudit.

Érudit est un consortium interuniversitaire sans but lucratif composé de l’Université de Montréal, l'Université Laval et l'Université du Québec à Montréal. Il a pour mission la promotion et la valorisation de la recherche. https://www.erudit.org/fr/ 


\title{
RÉMI BÉLAND
}

\section{Poaimes pour ne plus être seul}

\author{
(extraits)
}




\section{LA LÉGENDE DE L'ALLER-RETOUR}

Il y eut une fois: une longue route, des chemins et des chemins de distance, pleins de cahots, vides de sommeil. Un homme dur, comme la mort en lui, terrorisait l'homme de coeur, si faible devant tant de malheur. Le corps éreinté, les rides aux yeux, I'homme de coeur connaissait des chansons que I'homme de pierre aurait bien voulues dans sa bouche. Vomissant les dieux et fuyant la raison, I'homme de pierre clouait sa vie pour la détruire. Son malheur! il le jetait aux autres. Son bonheur était une lueur qui donnait pitié et sa tendresse ne venait qu'une fois l'an, à mots cachés, sans trop l'avouer. L'homme de coeur avait peur, peur de la pierre qui frappe le malheur d'un bon coup, d'un bon coup de vérité, de soleil et de repos.

Puis! une nuit de claire lune, sur l'autre rive, I'homme de coeur rencontra I'homme à la nature sage, à I'action silencieuse et à l'oeil alerte. La passion démesurée de l'homme à coeur raviva la musique de I'homme au pas sourd et profond. La lune allait être leur seule compagne. La musique, une jeune femme à séduire. Plus les trottoirs s'allongeaient, plus le vent poussait notre ami de coeur vers un horizon chantant. La mer s'approchait peu à mieux pour caresser les pieds nus de celui qu'elle venait de remettre au monde. La sueur coulait à flot sur un passé de violences mal foutu. Et la mer battait toujours des ailes pour celui qu'elle aimait de tout son coeur.

Corps et coeur, nous pouvions maintenant le voir venir comme un navire; houleux comme la vague, lent comme le silence. Son respir, c'était la mer et son amour touchait la berge comme un fruit de sable. "Vous viendrez?" demanda-t-il à la blonde dame de lune. "Oui, bien sûr!" fit-elle d'un doux quartier de sa voix. Joyeux, il prit bagages pour l'est en sifflotant le long de 
ses pas. Dame de lune, elle, arriva à temps pour tanguer du côté de la côte au fleuve, là où flânent les grands oiseaux blancs.

\section{CHEZ-NOUS}

Une grande maison verte et bâtarde, une cour grande comme plusieurs mains et deux hommes cachés à l'intérieur, deux hommes gratuits. Beaucoup de calme dans cette demeure, une table près de la fenêtre pour se voir et se raconter. Beaucoup de rire dans cette demeure, comme les couleurs d'un drapeau d'enfant en queue de chemise... Des pas lents et lourds. Et, des pas plus fébriles, plus nerveux. Des tuques, des mitaines, des bottes pleines de bouette, des foulards pleins de vent. Des assiettes, des tasses en masse, des lumières jaunes dans des fenêtres bleues. Des "respirs" très longs, des solitudes à deux, des "pleinitudes" à un. Des partages, des craintes, des frissons, des frictions, des mystères, des misères, de la bière et des pleurs parfois. Des préparations, des chants de chambre de bain, des "chéri! tasse-toi", des "pisses" ici, des pets là, des pyjamas et des "bonne nuit! Rémi", des bonnes nuits d'amis... 